\title{
Hepatite B: conhecimento e atitudes de acadêmicos de Odontologia
}

\author{
Hepatitis B: knowledge and attitudes of dentistry students \\ Hepatitis B: conocimiento y actitudes de académicos de odontología \\ Larissa Queiróz FERREIRA ${ }^{1}$ \\ Ana Carolina OSCHIRO ${ }^{1}$ \\ Marlene Cabral Coimbra da $\mathbf{C R U Z}^{2}$ \\ Renan Paes de CAMARGO ${ }^{3}$ \\ Marina Coimbra da $\mathbf{C R U Z}^{\mathbf{3}}$ \\ ${ }^{I}$ Graduanda do curso de Odontologia da Universidade Brasil - Campus Fernandópolis 15600-000 Fernandópolis-SP, Brasil \\ ${ }^{2}$ Docente dos cursos de Odontologia e Medicina da Universidade Brasil - Campus Fernandópolis \\ 15600-000 Fernandópolis-SP, Brasil \\ ${ }^{3}$ Graduando(a) do curso de Medicina da Universidade Brasil - Campus Fernandópolis 15600-000 Fernandópolis-SP, Brasil
}

\begin{abstract}
Resumo
Introdução: Os profissionais de saúde são grupo de risco em relação a hepatite B, por estarem diariamente expostos a patógenos em ambientes clínicos. A prevenção contra o vírus da hepatite $\mathrm{B}$ na prática odontológica está associada ao uso de equipamentos de proteção individual, desinfecção e esterilização dos equipamentos e materiais utilizados e também a manutenção da imunização ativa. Objetivo: Avaliar e comparar o conhecimento de acadêmicos iniciantes e concluintes de um curso de Odontologia sobre a hepatite B e suas formas de transmissão, prevenção, imunização e risco de acidente biológico. Material e Método: Estudo descritivo transversal, efetuado mediante a aplicação de questionário para levantamento sobre o conhecimento de 238 alunos ingressantes e concluintes de um curso de Odontologia. Resultados: Sobre a necessidade da utilização de Equipamentos de Proteção Individual em atendimentos clínicos, $87,4 \%$ responderam adequadamente a necessidade da utilização de todos os equipamentos. Apenas $20,2 \%$ dos alunos disseram terem sido vacinados com 3 ou 4 doses da vacina e 15,5\% afirmaram terem realizado o teste laboratorial para confirmação da soroconversão. Conclusão: É essencial que graduandos de Odontologia sejam conscientizados da importância da adoção das medidas preventivas com relação às doenças infectocontagiosas e cobertura vacinal antes de ingressarem na prática clínica, uma vez que, o acidente percutâneo é o fator de risco mais importante para a transmissão ocupacional da Hepatite B entre cirurgiões-dentistas.
\end{abstract}

Descritores: Hepatite B; Contenção de Riscos Biológicos; Riscos Ocupacionais.

\begin{abstract}
Introduction: Health professionals are a risk group of hepatitis B, because they are daily exposed to pathogens during clinical settings. Prevention of hepatitis B virus in dental practice is associated with the use of personal protective equipment, disinfection and sterilization of equipment and materials used and specially by immunization. Objective: To evaluate and compare the knowledge of beginning and finishing students of a Dentistry course on hepatitis B and its forms of transmission, prevention, immunization and risk of biological accident. Material and Method: Descriptive cross sectional study, done through the application of a questionnaire to survey the knowledge of 238 incoming and finishing students of a Dentistry course. Results: Regarding the need to use equipments for individual safety in clinical care, $87.4 \%$ responded adequately to the need to use all equipment. Only $20.2 \%$ of the students reported having been vaccinated with three or four doses of the vaccine and $15.5 \%$ stated that they had undergone the laboratory test to confirm seroconversion. Conclusion: It is essential that graduates of Dentistry be aware of the importance of adopting pre ventive measures regarding infectious diseases and vaccination coverage before entering clinical practice, since percutaneous accident is the most important risk factor for occupational transmission of Hepatitis B among dentists.
\end{abstract}

Descriptors: Hepatitis B; Containment of Biohazards; Occupational Risks.

\section{Resumen}

Introducción: Los profesionales de salud son un grupo de riesgo en relación a la hepatitis B, por estar diariamente expuestos a patógenos en ambientes clínicos. La prevención contra el virus de la hepatitis B en la práctica odontológica está asociada al uso de equipos de protección individual, desinfección y esterilización de los equipos y materiales utilizados y también el mantenimiento de la inmunización activa. Objetivo: Evaluar y comparar el conocimiento de académicos iniciantes y concluyentes de un curso de Odontología sobre la hepatitis B y sus formas de transmisión, prevención, inmunización y riesgo de accidente biológico. Material y método: Estudio descriptivo transversal, efectuado mediante la aplicación de cuestionario para el levantamiento sobre el conocimiento de 238 alumnos ingresantes y concluyentes de un curso de Odontología. Resultados: Sobre la necesidad de la utilización de equipos de protección individual en atendimientos clínicos, el 87,4\% respondió adecuadamente la necesidad de la utilización de todos los equipos. Sólo el 20,2\% de los alumnos dijo haber sido vacunados con 3 o 4 dosis de la vacuna y el $15,5 \%$ afirmó haber realizado la prueba de laboratorio para confirmar la seroconversión. Conclusión: Es esencial que los graduandos de Odontología sean conscientes de la importancia de la adopción de las medidas preventivas con relación a las enfermedades infectocontagiosas y cobertura vacunal antes de ingresar en la práctica clínica, ya que el accidente percutáneo es el factor de riesgo más importante para la transmisión ocupacional de la Hepatitis B entre cirujanos-dentistas.

Descriptores: Hepatitis B; Contención de Riesgos Biológicos; Riesgos Laborales.

\section{INTRODUÇ̃̃O}

As hepatites virais são um problema de saúde pública mundial, sendo responsáveis por 1,4 milhão de óbitos anualmente, principalmente pelas complicações das formas crônicas ou por hepatocarcinoma ${ }^{1}$.

A hepatite B é causada por um vírus da classe Hepadnaviridae, o Vírus da Hepatite B (HBV), que é infectante em superfícies do meio ambiente por pelo menos um mês a temperatura ambiente, sendo 57 vezes mais infeccioso que o Vírus da Imunodeficiência Humana (HIV) ${ }^{2}$

No período de 1999 a 2016, foram notificados 212.031 casos confirmados de hepatite B no Brasil, atingindo 6,9 casos para cada 100 mil habitantes no país em $2016^{1}$.

$\mathrm{O}$ diagnóstico para a hepatite $\mathrm{B}$ é baseado nos achados clínicos, laboratoriais e epidemiológicos. O diagnóstico definitivo da doença depende dos resultados de testes sanguíneos, sendo HBsAg o mais comumente utilizado. É o primeiro marcador da infecção, detectável em torno de 30 a 45 dias após a infecção, podendo ser realizado por meio de testes rápidos ou laboratoriais. A presença de HBsAg indica que uma pessoa é infectante, independente se a infecção é aguda ou crônica ${ }^{3}$.

A hepatite B é transmitida pelo sangue (via parenteral, percutânea e vertical), esperma e secreção vaginal (via sexual). Pode ocorrer pelo compartilhamento de objetos contaminados, como lâminas de barbear e acessórios de manicure, materiais para colocação de piercing e para confecção de tatuagens, além de instrumentos para uso de substâncias injetáveis. A transmissão também pode acontecer 
através de acidentes com exposição a material biológico, procedimentos cirúrgicos, odontológicos, hemodiálise, transfusão, quando as normas de biossegurança não são aplicadas. A transmissão vertical pode ocorrer no momento do parto ${ }^{3}$.

Devido a estabilidade do vírus no meio ambiente ser alta, há a possibilidade de que quantidades minúsculas $(0,0001 \mathrm{ml})$ de sangue ou secreções contendo esse agente sejam capazes de transmitir infecção ${ }^{2}$.

Deve-se levar em conta que as pessoas portadoras do HBV, através de seu sangue e outros fluidos já são infectantes aos outros indivíduos de duas a três semanas antes de surgirem os primeiros sinais da doença ${ }^{4}$.

A hepatite B é considerada uma doença ocupacional dos profissionais da saúde e está relacionada com o grau de exposição desses profissionais em seus ambientes laborais, por meio de sua relação direta com a manipulação de sangue de pacientes infectados pelo $\mathrm{HBV}^{5}$.

Os cirurgiões-dentistas são, portanto, grupo de risco em relação às doenças virais, incluindo a hepatite $\mathrm{B}$, por estarem diariamente expostos a patógenos, em ambientes clínicos e por seu alto poder infectante, devendo se manterem bem informados ${ }^{6}$.

A prevenção contra o $\mathrm{HBV}$ na prática odontológica está associada às medidas de precauções universais, como o uso de equipamentos de proteção individual (EPI) tanto para o profissional quanto para o pessoal auxiliar, desinfecção e esterilização dos equipamentos e materiais utilizados e também a manutenção da imunização ativa ${ }^{7,8}$.

Existe uma ocorrência maior de acidentes com materiais perfurocortantes em acadêmicos, e dentre os fatores que contribuem para isso estão a falta de habilidade e de segurança para a realização dos procedimentos ${ }^{2}$. Já a susceptibilidade dos estudantes à infecção pelo HBV é frequentemente associada à sua situação vacinal, e mesmo com a disponibilidade da imunização, ainda existem muitos graduandos e cirurgiões-dentistas que estão com o estado vacinal incompleto ou ausente $\mathrm{e}^{9,10}$.

A criação da vacina contra hepatite B, em 1981, e sua adoção tem contribuído para redução dessa infecção. Além da vacina, a disponibilidade de antivirais para tratamento da hepatite B crônica tem diminuído a carga dessa doença ${ }^{11}$.

A cobertura vacinal contra hepatite B é constituída por três doses, sendo a segunda realizada trinta dias após a primeira e a terceira dose cento e oitenta dias após a primeira. Para que haja sucesso na prevenção, a vacina deve ser administrada na quantidade de doses certas e no período de tempo recomendado ${ }^{4,12}$.

Existe um teste pós-vacinação, o anti-HBs, que tem como finalidade identificar a imunidade perante o $\mathrm{HBV}$, e aqueles que não obtiverem a resposta esperada necessitarão de uma revacinação. Este teste é especialmente recomendado para trabalhadores da saúde que tem contato direto com o paciente, podendo ser realizado entre 1 e 2 meses após a conclusão da série vacinal, para se obter informação definitiva sobre a resposta a vacina ${ }^{13}$.

O objetivo desta pesquisa foi avaliar e comparar o conhecimento de acadêmicos do primeiro e último anos do curso de Odontologia de uma universidade do interior de São Paulo (SP), sobre a Hepatite B e suas formas de transmissão, prevenção, imunização e situações de acidente biológico.

\section{MATERIAL E MÉTODO}

Realizou-se um estudo transversal, efetuado mediante a aplicação de um questionário para levantamento do conhecimento dos acadêmicos de Odontologia sobre a Hepatite B, suas formas de transmissão, prevenção e imunização. Esta pesquisa foi submetida à avaliação pelo Comitê de Ética em Pesquisa da Universidade Brasil, sob o CAAE 64556717.4.0000.5494.
Os dados foram coletados mediante a assinatura do Termo de Consentimento Livre e Esclarecido (TCLE) de 238 estudantes (com 18 anos ou mais e que concordaram em participar da pesquisa) que frequentavam o curso de Odontologia da Universidade Brasil - Campus Fernandópolis, no ano de 2017. Após a coleta de dados, os participantes foram informados sobre a importância do conhecimento sobre a Hepatite B e suas formas de prevenção, transmissão, imunização e condutas diante de acidentes biológicos.

\section{RESULTADOS}

Dentre as 238 pessoas (100\%) que responderam ao questionário, 169 (71\%) eram do sexo feminino e 69 (29\%) do sexo masculino, sendo que $116(48,7 \%)$ estavam cursando o primeiro ano do curso de Odontologia e $122(51,3 \%)$ estavam cursando o último ano.

Os acadêmicos foram questionados com relação aos fatores de risco para se contrair a hepatite $\mathrm{B}$, sendo que nessa questão poderia ser assinalada mais de uma resposta. O percentual de estudantes que afirmaram não fazer uso de preservativo durante relações sexuais foi o fator mais assinalado por ambas as turmas, sendo $41,4 \%$ de expostos no primeiro ano e $45 \%$ no último ano. Apesar de ter sido grande o percentual dos que admitiram não fazer uso de preservativos, $74,8 \%$ do total acreditam que o vírus é transmitido através de relação sexual.

Além disso, observou-se que $37 \%$ do primeiro ano afirmaram que não levam seus próprios materiais à manicure, contra $40 \%$ do último ano. Destes alunos, $17,2 \%$ tanto no primeiro quanto no último ano já passaram por alguma cirurgia geral; e $25 \%$ do primeiro ano e $30,3 \%$ do último ano passaram por cirurgia bucal (Tabela 1 ).

Tabela 1. Fatores de risco para contrair o vírus da Hepatite B assinalados pelos estudantes de Odontologia. Fernandópolis/SP, 2017.

\begin{tabular}{|c|c|c|c|c|c|c|}
\hline \multirow{2}{*}{$\begin{array}{c}\text { ATITUDES/ } \\
\text { FATORES DE RISCO }\end{array}$} & \multicolumn{2}{|c|}{$1^{\circ}$ ANO } & \multicolumn{2}{|c|}{ ÚLTIMO ANO } & \multicolumn{2}{|c|}{ TOTAL } \\
\hline & $N=116$ & $\%$ & $\mathrm{~N}=122$ & $\%$ & $\mathrm{~N}=238$ & $\%$ \\
\hline $\begin{array}{l}\text { Portador de HBV na } \\
\text { família }\end{array}$ & 2 & 1,7 & 4 & 3 & 6 & 2,5 \\
\hline $\begin{array}{l}\text { Passou por cirurgia } \\
\text { geral }\end{array}$ & 20 & 17,2 & 21 & 17,2 & 41 & 17,2 \\
\hline $\begin{array}{l}\text { Passou por cirurgia } \\
\text { bucal }\end{array}$ & 27 & 25 & 37 & 30,3 & 64 & 26,9 \\
\hline Fez tatuagem & 29 & 25 & 37 & 30,3 & 66 & 27,7 \\
\hline $\begin{array}{l}\text { Recebeu transfusão } \\
\text { sanguínea }\end{array}$ & 3 & 2,6 & 2 & 1,6 & 5 & 2,1 \\
\hline $\begin{array}{l}\text { Fez sexo } \\
\text { preservativo }\end{array}$ & 48 & 41,4 & 55 & 45 & 103 & 43,3 \\
\hline $\begin{array}{l}\text { Usa ou já usou drogas } \\
\text { injetáveis }\end{array}$ & 1 & 0,9 & 0 & 0 & 1 & 0,4 \\
\hline $\begin{array}{l}\text { Não leva os próprios } \\
\text { materiais na manicure }\end{array}$ & 43 & 37 & 49 & 40 & 92 & 38,6 \\
\hline $\begin{array}{l}\text { Nenhuma das opções } \\
\text { anteriores }\end{array}$ & 29 & 25 & 19 & 15,5 & 48 & 20,2 \\
\hline
\end{tabular}

Quanto ao conhecimento relacionado aos meios de transmissão da hepatite $\mathrm{B}$, conforme consta na Tabela 2, $87,9 \%$ e $91 \%$ do primeiro e último anos, respectivamente, souberam caracterizar acidente biológico com perfurocortantes como um meio de transmissão do vírus. Além disso, outras formas de transmissão mais reconhecidas pelos estudantes de maneira geral foram: compartilhamento de agulhas/seringas $(87,8 \%)$ e transfusão sanguínea $(76,5 \%)$.

A Figura 1 demonstra a situação vacinal relatada pelos alunos, sendo que a minoria deles, $11,2 \%$ no primeiro ano e $28,7 \%$ no último ano, disseram ter realizado a vacinação completa (com três ou quatro doses). Enquanto que, no que diz respeito a soroconversão da vacina, apenas 10 alunos do primeiro $(8,6 \%)$ e 27 do último $(22,1 \%)$ relataram terem avaliado a efetividade de sua vacinação pelo Anti-HBs. Além disso, $62(53,5 \%)$ primeiranistas e $56(45,9 \%)$ do último ano não souberam responder a tal pergunta. No total, 20,6\% dos alunos de ambos os anos afirmaram não terem realizado o teste de soroconversão e 49,6\% não souberam responder. 
Tabela 2. Formas de transmissão do vírus da Hepatite B reconhecidas pelos alunos de Odontologia avaliados. Fernandópolis/SP, 2017

\begin{tabular}{l|c|c|c|c|c|c}
\hline \multicolumn{1}{c}{$\begin{array}{c}\text { FORMAS DE } \\
\text { TRANSMISSÃO }\end{array}$} & \multicolumn{2}{c|}{$\mathbf{1}^{\circ}$ ANO } & \multicolumn{2}{c|}{ ÚLTIMO ANO } & \multicolumn{2}{c|}{ TOTAL } \\
\cline { 2 - 8 } & $\mathbf{N = 1 1 6}$ & $\%$ & $\mathbf{N = 1 2 2}$ & $\%$ & $\mathbf{N = 2 3 8}$ & $\%$ \\
\hline Transmissão vertical & 38 & 32,7 & 56 & 45,9 & 94 & 39,5 \\
\hline Saliva Humana & 39 & 33,6 & 58 & 47,5 & 97 & 40,8 \\
\hline Relação sexual & 85 & 73,3 & 93 & 76,2 & 178 & 74,8 \\
\hline $\begin{array}{l}\text { Compartilhamento de } \\
\text { seringas e agulhas }\end{array}$ & 101 & 87 & 108 & 88,5 & 209 & 87,8 \\
\hline $\begin{array}{l}\text { Transfusão sanguínea } \\
\text { Acidentes com } \\
\text { perfurocortantes }\end{array}$ & 82 & 70,7 & 100 & 82 & 182 & 76,5 \\
\hline Não soube responder & 2 & 87,9 & 111 & 91 & 213 & 89,5 \\
\hline
\end{tabular}

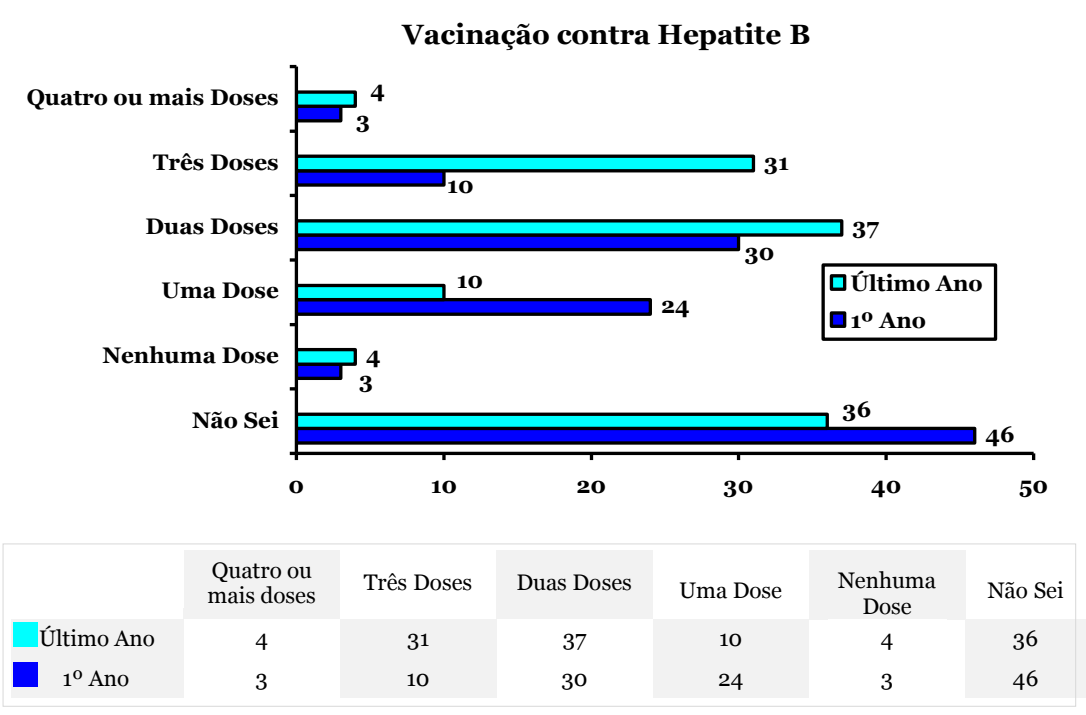

Figura 1: Estado vacinal para Hepatite B relatado pelos graduandos do primeiro e último anos do curso de Odontologia. Fernandópolis/SP, 2017.

Sobre a questão da biossegurança, 91,8\% dos alunos do último ano e $82,8 \%$ dos do primeiro souberam responder corretamente quais são os Equipamentos de Proteção Individual (EPI) necessários para prevenir infecções pelo vírus da hepatite B ao realizar procedimentos de saúde.

Ao serem questionados sobre as chances de infecção do HBV na prática ocupacional em relação as chances de infecção pelo HIV, poucos detiveram conhecimento correto no último período (32\%). Já os discentes ingressantes do curso mostraram-se bastante confusos sobre qual dos vírus representa maior risco ocupacional, de forma que $70,7 \%$ não souberam responder ou responderam errôneamente este quesito. Os dados encontram-se dispostos na Figura 2.

$\mathrm{Na}$ questão referente a atitude a ser tomada pelos graduandos em situação de acidente biológico, 67,2\% dos alunos do primeiro ano procederiam corretamente, lavando o local com água e sabão e comunicando o professor responsável a respeito. Dentre os alunos do último ano, $66,4 \%$ deles agiriam corretamente em acidentes biológicos.

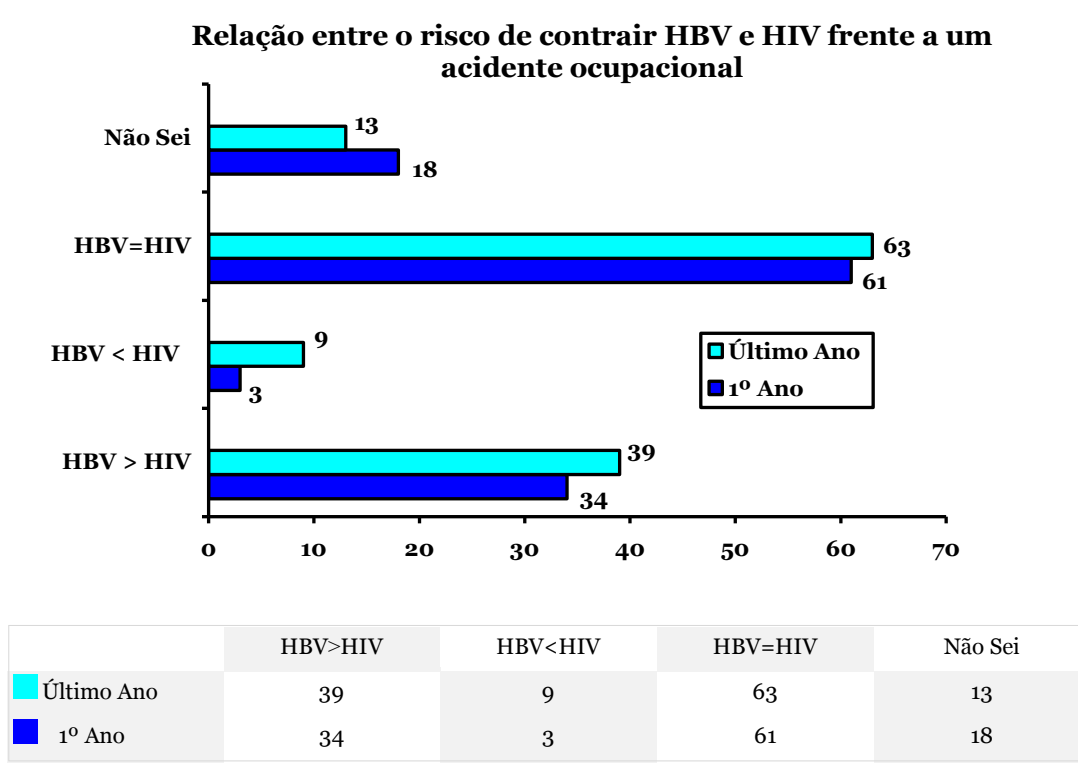

Figura 2: Risco de contrair o HBV comparado ao de contrair o HIV. Fernandópolis/SP, 2017.

\section{DISCUSSÃO}

A exposição do cirurgião-dentista aos agentes biológicos o coloca em maior risco em relação a outros profissionais, inserindo a obrigatoriedade de um conhecimento atualizado sobre as doenças infectocontagiosas. Assim, são necessárias medidas preventivas de imunização e protocolos de biossegurança que devem ser seguidos corretamente ${ }^{14}$.

Apesar de existirem várias formas de contágio, o principal meio de contaminação de profissionais da saúde utilizados durante os procedimentos clínicos, como agulhas e material biológico ${ }^{10}$. Aos graduandos de Odontologia soma-se a inexperiência clínica e o número de alunos não vacinados ou com número de doses insuficientes, o que os coloca em maior risco de serem infectados pelo $\mathrm{HBV}^{15}$.

Neste estudo, a via hematológica foi reconhecida como meio detransmissão do vírus por grande parte dos alunos avaliados: transfusão sanguínea (76,5\%), compartilhamento de seringas/agulhas por usuários de drogas $(87,8 \%)$ e acidentes com perfurocortantes $(89,5 \%)$. Com relação a possibilidade de transmissão sexual deste vírus, $74,8 \%$ do total dos alunos relataram conhecimento sobre essa via de transmissão, apesar de $43,3 \%$ dos alunos terem relatado comportamento de risco ao não fazer uso de preservativo. Este resultado corrobora com o estudo de Ângelo et al. ${ }^{16}$, em que os pesquisados também relataram serem os procedimentos cirúrgicos $(92,5 \%)$ e a via hematológica $(88,1 \%)$ os meios mais prováveis de contaminação.

O trabalho de Oliveira et al. ${ }^{14}$ revelou que $91,3 \%$ dos alunos afirmaram serem os acidentes com perfurocortantes uma dessas formas e somente $6,6 \%$ afirmaram não conhecer as formas de transmissão da doença. Já no presente estudo, $87,9 \%$ dos alunos do primeiro ano e $91 \%$ dos alunos do último ano responderam que acidentes com perfurocortantes é sim uma forma de transmissão do HBV e, apenas $1,7 \%$ dos alunos do primeiro ano dizem desconhecer as formas de transmissão.

O HBV é um vírus que apresenta maior infectividade que o HIV, e diante deste questionamento, este estudo observou que $29,3 \%$ do primeiro ano responderam ser o HBV mais infectante e $32 \%$ do último ano, o que demonstra o ainda desconhecimento destes frente ao assunto ${ }^{17}$.

A imunização, por meio de três doses da vacina é uma das medidas de prevenção da hepatite B. ${ }^{9}$ Mas mesmo com a disponibilização da imunização ainda há graduandos e profissionais de Odontologia que estão com o estado vacinal incompleto ou ausente ${ }^{14}$.

Segundo o relato dos graduandos pesquisados, apenas $11,2 \%$ do primeiro ano tomaram 3 ou 4 doses da vacina e $28,7 \%$ do último ano. Com relação a não vacinação ou vacinação incompleta, $2,6 \%$ dos alunos do primeiro ano afirmaram não terem tomado vacina e $39,6 \%$ não souberam responder; dentre os concluintes, $3,3 \%$ dos que relataram não serem vacinados, $29,5 \%$ não souberam responder. Este estudo demonstra um resultado muito inferior ao verificado por Abich et al. ${ }^{18}$, que ao entrevistar estudantes de Biomedicina, avaliaram que $60,2 \%$ haviam recebido três doses da vacina. Ângelo et al. ${ }^{16}$ em pesquisa com alunos de Odontologia, $72,1 \%$ disseram terem sido vacinados contra a Hepatite B, no entanto, somente 50\% apresentam esquema vacinal completo, e apenas $9,9 \%$ fizeram verificação da soroconversão após 3 doses da vacina. Porém, assim como Souza e Teixeira ${ }^{19}$, verificamos que os graduandos que já frequentam as disciplinas clínicas do curso de Odontologia detêm melhor conhecimento sobre sua situação vacinal quando comparado aos alunos ingressantes.

Além da vacinação completa, o Ministério da Saúde recomenda para trabalhadores da saúde, que após 30 dias da completude do esquema, sejam realizados exames sorológicos 
(Anti-Hbs) para verificação da soroconversão e confirmação da proteção segura, sendo essencial para a prevenção da transmissão ocupacional da doença ${ }^{9}$. Apenas $15,5 \%$ dos graduandos avaliados relataram ter realizado o teste para Anti-HBs, sendo que a conduta a ser tomada frente um acidente biológico depende deste resultado de soroconversão. Dessa forma, o desconhecimento do resultado deste teste retarda as medidas preventivas pós-exposição. ${ }^{20}$ Vieira et al. ${ }^{21}$ verificaram a soroconversão de 58 acadêmicos da área da saúde. Nos acadêmicos que receberam somente uma dose da vacina, a soroconversão foi observada em apenas $12,5 \%$. No grupo que recebeu 2 doses, a soroconversão foi de $72,72 \%$, enquanto uma soroconversão de $82,14 \%$ foi observada nos alunos com esquema completo de vacinação. A partir destes resultados encontrados, torna-se necessário que acadêmicos da odontologia sejam incentivados a completarem o seu esquema vacinal, obtendo assim maior percentual de soroconversão.

Este estudo observou, enfim, que poucos alunos estavam cientes dos riscos que encontrariam ao ingressar no curso de Odontologia, visto que $15,5 \%$ dos acadêmicos do primeiro ano não souberam responder se o curso representa uma profissão de risco para contrair o vírus. Este resultado vem de encontro ao estudo de Garcia et al. ${ }^{17}$ que também observou que a maioria dos ingressantes em cursos na área da saúde não possuem o devido conhecimento sobre os riscos aos quais serão expostos, sendo as universidades responsáveis por fornecer as informações adequadas sobre este assunto no começo do curso.

\section{CONCLUSÃO}

Conclui-se que os acadêmicos de Odontologia adquiriram algum conhecimento ao longo da sua graduação sobre a Hepatite B e formas de prevenção aos acidentes biológicos no ambiente clínico, porém, estes alunos apresentam também comportamentos de risco fora do ambiente clínico, como o não uso de preservativos para relações sexuais. Ficou evidenciado também que o status vacinal de muitos não estava em dia, além de não terem realizado o teste Anti-HBs.

Este estudo reforça a necessidade de maiores orientações, principalmente quanto às medidas preventivas no ambiente clínico em relação ao risco biológico da profissão e também em situações cotidianas.

\section{REFERÊNCIAS}

1. Brasil. Ministério da Saúde. Secretaria de Vigilância em Saúde. Boletim Epidemiológico. Hepatites Virais. Brasília: Ministério da Saúde. 2017; 48(24): 68p.

2. Brasil. Ministério da Saúde. Secretária de Políticas de Saúde. Coordenação Nacional de DST e Aids. Controle de infecções e a prática odontológica em tempos de Aids: manual de condutas. Brasília (DF); 2000.

3. Brasil. Ministério da Saúde. Secretaria de Vigilância em Saúde. Coordenação-Geral de Desenvolvimento da Epidemiologia em Serviços. Guia de Vigilância em Saúde: volume 2. $1^{\text {a }}$. ed. atualizada. Brasília: Ministério da Saúde, 2017.

4. Ferreira CT, Silveira TR. Hepatites virais: aspectos da epidemiologia e da prevenção. Rev bras epidemiol. 2004; 7(4):473-87.

5. Costa FM, Martins AMEBL, Lima CA, Rodrigues QF, Santos KKF, Ferreira RC. Fatores associados à verificação da imunização pós-vacinação contra hepatite B entre trabalhadores da Atenção Primária. Cad saúde colet. 2017; 25(2):192-200.

6. Gillcrist JA. Hepatites viruses A, B, C, D, E and G: implications for dental personel. J Am Dent Assoc. 1999; 130(4):509-20.
7. Martins AMEBL, Barreto SM. Vacinação contra a hepatite B entre cirurgiões dentistas. Rev Saúde Pública. 2003; 37(3):333-38.

8. Pinelli C, Garcia PPNS, Campos JADB, Dotta EAV, Rabello AP. Biossegurança e Odontologia: crenças e atitudes de graduandos sobre o controle da infecção cruzada. Saúde Soc. 2011; 20(2):448-61.

9. Souza FO, Freitas PSP, Araújo TM, Gomes MR. Vacinação contra hepatite $B$ e Anti-HBS entre trabalhadores da saúde. Cad. saúde colet. 2015; 23(2):172-79.

10. Pereira FS, Costa SM, Gusmão BM, Costa FM, Matos FV, Dias OV. Infecção pelo vírus da hepatite B em profissionais e acadêmicos da saúde: revisão de literatura. Intercâmbio. 2017; 10:35-46.

11. Teles SA. Viral hepatitis: a challenge for nursing. Rev Bras Enferm. 2017; 70(2):231-32.

12. Freitas DA, Maurício CC, Santos ALD, Caballero AD, Hernandez CIV, Pereira MM. Conhecimento de acadêmicos de odontologia sobre hepatite $\mathrm{B}$. Rev bras cir cabeça pescoço. 2011; 40(1):30-3.

13. Chaves PI, Links R, Gallo TB, Garcia RS. Verificação do conhecimento sobre hepatite B. RGO. 2002;50(1):17-20.

14. Oliveira RHG, Almeida TF. Riscos Biológicos em Odontologia: uma revisão da literatura. Rev Bahiana Odonto. 2015; 6(1):34-46.

15. Oliveira VC, Guimarães EAA, Costa PM, Lambert CC, Morais PMG, Gontijo TL. Situação vacinal da hepatite B de estudantes da área da saúde. Rev Enf Ref. 2013; serIII(10):119-24.

16. Ângelo AR, Queiroga AS, Gonçalves LFF, Santos SD, Sousa CFS, Soares MSM. Hepatite B: conhecimento e prática dos alunos de Odontologia da UFPB. Pesq Bras Odontoped Clin Integr. 2007; 7(3):211-16.

17. Garcia LP, Blank VLG. Prevalência de exposições ocupacionais de Cirurgiões-dentistas e auxiliares de consultório dentário a material biológico. Cad Saúde Pública. 2006; 22(1):97-108.

18. Abich DR, Lima GCS, Lissarassa YPS, Mallet EKV, Comparsi B. Imunização contra o vírus da Hepatite B em estudantes da área da saúde. Contexto \& Saúde. 2016; 16(30):77-84.

19. Souza EP, Teixeira MS. Hepatitis B Vaccination coverage and postvaccination serologic testing among medical students at a publica university in Brazil. Rev Inst Med Trop. 2014; 56(4):307-11.

20. Barbosa ASAA, Salotti SRA, Silva SMUR. Nível de conhecimento sobre Hepatite B, estado vacinal e medidas de biossegurança de profissionais de enfermagem em um hospital público do interior paulista. R Epidemiol Control Infec. 2017; 7(2):107-12.

21. Vieira TB, Pereira R, Santos KF, Leal DBR. Soroconversão após a vacinação para Hepatite $\mathrm{B}$ em acadêmicos da área da saúde. Disc Scientia. 2006; $7(1): 13-21$.

\section{CONFLITO DE INTERESSES}

Os autores declaram não haver conflitos de interesse.

\section{AUTOR PARA CORRESPONDÊNCIA}

Marlene Cabral Coimbra da Cruz

mcoimbracruz@gmail.com

Submetido em 06/05/2018

Aceito em 30/05/2018 